\title{
El tipo sicológico en Eduardo Barrios y correspondencias en las letras europeas
}

$\mathrm{H}^{L}{ }_{\text {discurso y los gestos de los protagonistas por un lado, y en el aden- }}$ trarse en los móviles tan sólo pensados, en las tranformaciones de los sentimientos antes de su manifestación por el otro, ha hecho que los criticos hayan llamado a su novela alternativamente realista o sicológica. Aparte de que estos términos utilizados como rótulos tienen a veces poco valor -en cuanto se usan de un modo impreciso o difuso-, resulta difícil no ver lo sicológico en estas novelas después de la crítica ya clásica sobre la novela europea del siglo xIx, como el prólogo a Pièrre et Jean de Maupassant, o la dilucidación sobre el método de observación sicológica en la tragedia que se encuentra en la tercera parte de Le rire de Bergson, etc.

Arturo Torres Rioseco apuntó en la dirección justa en su obra Grandes novelistas de la América bispana. ${ }^{1}$ En un artículo más reciente, Carlos D. Hamilton ha puesto la cuestión en términos claros y precisos que recuerdan la distinción clásica a que nos referimos más arriba: "Los críticos han insistido en el carácter autobiográfico de las novelas de Barrios. Hasta el punto de llegar algunos a negar que la obra del novelista chileno contenga más sicología que la de un autoanálisis. Es claro que algunas experiencias del autor son trasladadas a sus personajes; pero no hay que olvidar que el primer laboratorio, acaso el único cierto, de observación sicológica de los otros sea el propio autoanálisis". ${ }^{2}$

1 University of California Press, 1949, II, 21-58.

"La novelística de Eduardo Barrios", Cuadernos Americanos. XV, I (EnFeb. 1956), 283. 
Ahora bien: no sólo observa e interpreta Barrios los procesos síquicos de los otros; sus novelas nos descubren un interés que va más allá del desarrollo artístico del personaje y que se manifiesta en la sicología misma, hasta el punto de que a veces se le escapan ${ }^{3}$ afirmaciones que pertenecen a la intuición científica más que a la literatura. Barrios ve una distribución polar de los tipos humanos, con concomitancias sexuales, en lo cual se halla en una tradición tan antigua como el pensamiento occidental. En esta línea sus personajes muestran correspondencias notables con los de otros escritores de las letras europeas - tema éste que merece el tratamiento extenso de un libro. Aquí nos limitaremos al estudio de una sola novela de Barrios, Un perdido; anotaremos coincidencias con los tipos de Ernst Kretschmer - de mayor influencia en España y en los circulos intelectuales de habla española-, y en cuanto a correspondencias literarias nos referiremos más extensamente a la novela de Flaubert $L$ 'éducation sentimentale, ${ }^{4}$ y traeremos ejemplos de otros autores que revelan un interés, un esfuerzo semejante al de Barrios por penetrar el secreto de la organización íntima del carácter - la sucesión de notas coincidentes indicarán una línea común de experiencia y tradición con el autor chileno.

\section{EL TIPO REFRACTO}

Por un lado tenemos a los personajes que muestran una estructura compleja, REFRACTA, ${ }^{5}$ de la personalidad, que los hace permanentemente

3 "Se le escapan", y por su brevedad y expresión original no molestan; tal como dice Hamilton, Barrios se halla libre de "pedanterías pseudocientíficas, tan en boga en los 'psicologizantes' (acaso por eso Onís le niega el atributo [de sicológico])".

4 La ascendencia de ésta ha sido mencionada en el prólogo de Manuel Gálvez a la edición de Un perdido de que nos serviremos (Madrid, 1926, I, 12) y en la obra citada de Arturo Torres Rioseco (II, 37-43).

5 Al introducir los términos refracto y espontáneo tratamos de $1^{\circ}$ ) mantener nuestra actitud ingenua - también quiere decir libre-; $2^{\circ}$ ) conservar términos que son más simples y por tanto, más significativos; $3^{\circ}$ ) poner la comparación con los tipos de Kretschmer en su justa perspectiva, pues más adelante no nos ayudará en el rumbo que seguiremos. Nos parece que al considerar los ejemplos de la literatura la clasificación del siquiatra alemán "da en la tecla" más a menudo que las otras clasificaciones interpretativas con las que guarda cierta semejanza, y por tanto encontraremos en ella apoyo para nuestras observaciones. Kretschmer partió del estudio de enfermos mentales, divididos en dos grandes clases, y creyó encontrar los elementos que distinguen a dos grandes "temperamentos" normales, a los que llamó esquizotímico y ciclotímico. El esquizotímico corresponde más o menos (aunque algunos aspectos no están claros, especialmente en cuanto a la trillada introextraversión) al tipo subjetivo de Binet, al integrado de Jaensch, al introvertido de Jung, al taquipsíquico de Pende, entre otros; el ciclotímico, respectivamente, corresponde al objetivo, desintegrado, extravertido, bradipsíquico. Para nuestro cotejo usaremos la edición de Berlín, 1936, de Körperbau und Charakter. 
conscientes -y por lo mismo más o menos inseguros- de sí mismos, aun en situaciones que normalmente debieran provocar su total participación. Es como si los acontecimientos sólo consiguieran afectarlos en una faz, más o menos extensa, de su ser, mientras otra permanece aparentemente indiferente, dedicada a comentar u observar el curso del acontecer o simplemente aparte del mlismo - y lo más complicado o contradictorio del caso: la faz que queda afectada es hipersensible. ${ }^{6}$

Luis Bernales había llegado a sentir que "la llevaba [a Teresa] compenetrada con su sangre, sin remedio" (II, 239), y la había perdonado a continuación de su infidelidad. Por ella había luchado con un amigo de oficina, ciego de ira, por primera vez en su vida. Después de la traición de Teresa y del perdón -abyecto de acuerdo al consenso social- de Luis, éste vuelve un día a su casa para encontrarse con que su mujer, la que él sentía compenetrada con su sangre, acaba de abandonarlo sin aviso. En. tonces, Lucho sigue unos pasos, "teatral"." Continúa el proceso hacia una desolación fría, cuando un verso le brota "de la memoria de un modo definitivo. ¿Quién detiene al amor cuando se va?" Luego, mientras su vecino y compañero de desgracia se afana en la búsqueda de su mujer legítima, a Luis - que se deja arrastrat por el otro- sólo le viene a la cabeza el cxtrañarse de no tener conciencia de un dolor (II, 253-255). En otro momento crítico de su vida Luis siente una "indiferencia que a él mismo le pasma" (II, I46).

Frédéric Moreau muestra este situarse en espectador de sí mismo: ' $[$...] ne retrouvant plus Mme Arnoux dans le milieu où il l'avait connue, elle luit semblait avoir perdu quelque chose, porter confusément comme une dégradation, enfin n'être pas la même. Le calme de son coeur le stupéfiait". ${ }^{8}$ Aquí también el protagonista siente que esa insensibilidad no está en su lugar, con casi las mismas palabras que Luis.

- Al estudiar la "proporción sicoestésica" en los que llama temperamentos esquizoides o esquizotímicos, Kretschmer observa la mezcla de hipersensibilidad y frialdad en el mismo individuo y la ilustra con una cita literaria: "Er ist ein 'Tropfen feurigen Weins in einem Fass von Eis', sagt Hebbel sehr hübsch über den gesunden Schizothymen Uhland" (pág. 140. Traducimos: Es una gota de ardiente vino en un tonel de hielo, dice muy bellamente Hebbel del esquizotímico sano Uhland).

7 Hay que tener cuidado con este término, pues Lucho no es teatral en el sentido de mostrar énfasis o exageración pasional, ironía, etc., y no es tampoco lo que se entiende por fingimiento. Se trata aquí de un representar la vida en lugar de vivirla. Para ver claro, nada mejor que observar el contraste diametral con lo que Barrios llama "cómico" (= actor) en el tipo humano opuesto: "Anselmo sabía intercalar exclamaciones quedas y cortadas; modular apenas, en voz cálida y opaca, matices de una sensibilidad finísima que un carácter entero y varonil sofrenaba hermosamente... iOh grandísimo cómico!..." (II, 138).

8 L'éducation sentimentale (Genève: Editions du Milieu du Monde), 173-174. 
Naturalmente esa conciencia separada del actuar y sentir estimula un constante raciocinar y por otra parte - tal como observamos al principioreduce la seguridad sobre los juicios éticos y prácticos en general y la capacidad de resolverse. José Ignacio Arcelu, en El mundo es ansi, nos deja penetrar en la organización de este carácter, en un corto párrafo, claro como un esquema: "Cualquier cosa que otro resuelve instintivamente, yo tengo que resolver por razonamiento. Desde ponerme los pantalones hasta salir a la calle, he de ir calculando todos los días si sería mejor hacer o no hacer". 9

Esta inseguridad se ejemplifica a lo largo de todo el libro de Barrios. Recordemos cuando Lucho, recién llegado de Iquique - ya un muchacho completamente desarrollado y con abundante experiencia sexual-, en una permanente lucha y examen de conciencia, se siente "más niño que nunca enfrente de esos seres resueltos" - -su familia paterna- (II, 29). Ya desde niño - niño de verdad esta vez - frente a su padre: "Él no me castiga; pero se fija tanto en lo que digo [agrandado por su propio exceso de autocrítica e inseguridad], que $[\ldots]$ se me figura que puedo decir alguna cosa que le parezca mal" $(I, 29) .^{10} \mathrm{La}$ inseguridad se experimenta de igual modo sobre lo pasado, lo cual es causa de remordimientos típicos, ${ }^{11}$ como cuando se siente "culpable de haber hecho un daño al cadáver" de la madre $(I, 98)$ o cuando siente "oleadas de vergüenza secreta, de honda pesadumbre, y deseos exasperados de borrar de su pasado" (I, 44) la conducta desairada en un baile infantil de máscaras - seguramente los demás ni habrian caído en cuenta o se habrían olvidado en seguida de su "con. ducta desairada".

Esta misma siquis refracta y exceso de autocrítica consiguiente estorban toda expresión espontánea, lo cual determina que las mejores respuestas se le ocurran a Lucho demasiado perfectas y demasiado tarde - - el típico esprit d"escalier que atormentó a Rousseau. En el mismo baile infantil, donde un chico disfrazado de oso le "gruñe" "Arlequín pavo", "él

9 Colección Austral, 1943, 126.

10 Kretschmer observa este rasgo en el esquizotímico: "Ein beständiges überreiztes Selbstanalysieren und Vergleichen: Wie wirke ich? Wer tut mir Unrecht? Wo habe ich mir etwas vergeben? Wie setze ich mich durch?" (pág. 144-Una permanente y sobreexcitada comparación y análisis de sí mismo: ¿qué efecto causó? ¿quién hablará mal de mí? ¿en qué me he comprometido [mi reputación]? ¿cómo me fué?").

11 No originados en el sentimiento del pecado o necesariamente complicados con el mismo - Como cuando Frédéric oye comentar que Mme Arnoux es una mujer "honnête" (pág. 73). Se trata de la conciencia no del alma que se ha hecho sino de lo mal que se ha actuado, del malogro, el fiasco, la culpa o el sentimiento del ridículo. Cuanto más refracción y vuelta de la conciencia, más exacerbamiento del amor propio. 
piensa una réplica oportuna, aguda, que engríe su amor propio y le reconcilia consigo mismo; sin embargo, otro viene, le espeta nueva broma... y el aún está perfeccionando, puliendo in mente la réplica anterior ya perdida..." (I, 50). Baroja nos ha dado en $E l$ mundo es ansí un pasaje extrañamente parecido al del baile de máscaras de Barrios. Oigamos la confidencia de Arcelu: "De pequeño, una cosa que me preocupaba era el Carnaval; creía que bastaba ponerse la careta para que uno se sintiera vivo, ingenioso, lleno de gracia. Un domingo de Carnaval, en el Puerto de Santa María, me vestí de máscara y salí a la calle. Vi pasar a un amigo y me acerqué a él dispuesto a embromarle. ¡Adiós! ¡Adiós!, le dije, y no pude salir de ahí. Avergonzado, fui al paseo de la Victoria, me quité la careta ${ }_{2}$ me senté en un banco y casi estuve a punto de romper a llorar" (págs. I26-127).

La misma lentitud y falta de espontaneidad se encuentra en Frédéric Moreau. Frédéric siente un "singular besoin de [...] revoir" Arnoux. Éste se sorprende de la visita y exclama:

-Tiens! qui vous ramène?

Cette question bien simple embarrassa Frédéric; et, ne sachant que répondre, il demanda si l'on n'avait point trouvé par hasard son calepin, un petit calepin en cuir bleu.

-Celui où vous mettez vos lettres de femmes? dit Arnoux.

Frédéric, en rougissant comme une vierge, se défendit d'une telle supposition.

-Vos poésis, alors? répliqua le marchand (Pág. 79).

Son bromas comunes, con algo de tomadura de pelo al muchacho raro, y a Frédéric no le viene una ocurrencia sociable a tiempo - cualquier palabrita o chiste de los que se oyen todos los días- porque no se pone al nivel de la broma, ${ }^{12}$ porque las relaciones con los otros tienen siempre en este tipo un algo de violencia y de demasiado trastorno interior e im. portancia excesiva. ${ }^{13} \mathrm{~A}$ lo que se suma que de pronto siente la inseguridad de sí mismo y 'de sus actos, el desquicio de sus propios impulsos.

12 Tener en cuenta la falta de sentido del humor que atribuye Kretschmer a su esquizotímico (pág. 148, décima línea), y el hecho de que frecuentemente es objeto de burla (pág. 147, párrafo línea 5), la cual lo afecta en demasía debido a su excesiva sensibilidad.

${ }_{13}$ En el sentido de "dar demasiado peso, demasiada importancia a las cosas"; aquél "algo" de trastorno varía en una escala que va desde un matiz en una personalidad perfeccionada, lograda, hasta una total anestesia emocional e importancia de comunicación en una siquis anormal —según Kretschmer. "Dass aus dieser psychästhetischen Proportion ein grundfalsches Bild des gegenseitigen Bedeutungswertes von Ich und Aussenwelt entstehen muss, ist ohne weiteres einfühlber" 
Esta falta de espontaneidad, de naturalidad, DE SIMPLICIDAD, lleva a reacciones o comportamientos imprevisibles, desarticulados, que no están de acuerdo con las circunstancias. Cuando la abuela cae y se mata, el niño al principio huye "en carrera despavorida, lanzanido gritos de espanto". Encuentra al abuelo y le suelta "mamá Gertrudis se ha matado", y lo hace "sonriendo, presa de la inversión frecuente en los seres nerviosos" (I, 78). ${ }^{14}$ Aún más imprevisible resulta su comportamiento en el plano de lo social. Sus actos aparecen a veces insólitos, o de una franqueza impúdica, pues no se apoyan en el hábito, las conveniencias, la costumbre pura y simple que es la fácil norma de espíritus menos estratificados -hasta los "más tarambanas". En un prostíbulo de Iquique a un muchacho le sale decirle a Lucho "- Chit! Eso no se habla en voz alta, bárbaro" ( $I, 246)$. Poco después, por diferente motivo, otros exclaman "-iLucho! iQué bárbaro!"' (I, 248).

El carácter refracto es también un obstáculo formidable para la irritación normal, es decir, la que no se detiene desde que brota hasta que estalla en palabras o hechos. El pasaje de magistral realismo en que la Petitpois acusa de ladrón a Lucho en la cantina de un prostíbulo es ilustrativo al respecto, más aún por el contraste entre la reacción violenta y espontánea de la Ana Portela y la fría o timorata o compuesta de Luis (I, 24I-244). La ira se da comúnmente en estos caracteres de un modo teatral, es decir, representan más que sienten una ira que creen justificada o proporcionada; en otros casos existe el movimiento de la ira verdadera,

(pág. 140 -es comprensible que de esta proporción sicoestésica debe resultar una representación completamente falsa de la importancia recíproca del yo y el mundo extetior). Sigue Kretschmer en el capítulo siguiente: "Ihr Autismus ist ein schmerzhaftes Sich-in-sich-selhst Zusammenkrampfen" (pág. 141-su autismo es un doloroso encogerse dentro de sí mismo). A Lucho le alcanzan las dos afirmaciones que preceden; a Frédéric probablemente sólo la primera. Sobre la timidez en este tipo: "Die Schüchternheit ist [...] ein hyperästhetischer Einstellungsaffekt beim Eintritt fremder Personen in den autistischen Bannkreis der schizoiden Persönlichkeit [...] Dieser überstarke Reiz strahlt tetanisch lähmend in Gedankenablauf und Körpermotilität aus" (pág. 142- la timidez es una inhibición hiperestésica a la entrada de personas extrañas en el excluyente círculo de la personalidad esquizoide; este excesivamente violento estímulo se itradia y paraliza tetánicamente la ideación y la motilidad). Lo anterior se relaciona a una actitud general de indefensa ansiedad frente a situaciones inesperadas -." die hilflose Ängstlichkeit gegenüber neuen ungewohnten Situationen"- Los rasgos que dejamos expuestos explican que los sujetos de este tipo sean completamente insociables, o practiquen una sociabilidad ecléctica en pequeños círculos selectos, o sean superficialmente sociables sin una profunda relación síquica con el ambiente (actitudes que se ejemplifican a lo largo de las vidas de Lucho y Frédétic): "Schizoide Menschen sind nämlich entweder absolut ungesellig, oder eklektisch gesellig im kleinen geschlossenen Zirkel oder oberflächlich gesellig ohne tieferen seelischen Rapport mit der Umgebung" (pág. 141).

14 Aditamento explicativo este último que está de más en novela y nos descubre por tanto la aplicación del pensamiento de Barrios a la materia sicológica. 
pero se escapa por la imaginación, no se manifiesta y se revierte dentro, o cuando finalmente se abre paso ya es demasiado tarde, fuera de lugar o de proporción, y entonces se resuelve a veces en manifestaciones histéricas: cuando niño, en el baile de máscaras, "sufre una cólera llorosa contra sí mismo" (I, 50); ya hombre joven,

como esos gritos de pavor que suelen oírse en la calma hueca de la noche, alaridos que nos sobresaltan como el eco de una tragedia cayendo en la soledad de nuestro dormitorio, y que descargan un calofrío doloroso a través de nuestra médula, y nos crispan de coraje las entrañas, y en el cerebro nos dejan un latido violento y en el pecho una angustia que nos impide dormir, así sobrecogía el ánimo de Lucho la perspectiva de la Escuela Militar cada vez que se le representaba. Quedaba perturbado, sufría iras violentas y se abatía por fin como quien se ve en el fondo de un pozo sin salida (I, 214).

También en Frédéric Moreau las pasiones - en este caso el deseo o los celos- no se manifiestan y acaban en histerismo:

Une chose l'étonnait, c'est qu'il n'était pas jaloux d'Arnoux; et il ne pouvait se la figurer autrement que vêtue, tant sa pudeur semblait naturelle, et reculait son sexe dans une ombre mystérieuse.

Cependant, il songeait au bonheur de vivre avec elle, de la tutoyer, de lui passer la main sur les handeaux longuement, ou de tenir par terre, à genoux, les deux hras autour de su taille, à hoire son âme dans ses yeux! Il aurait fallu, pour cela, subvertir la destinée; et, incapable d'action, maudissant Dieux et s'accusant d'être lâche, il tournait dans son désir, comme un prisonnier dans son cachot. Une angoisse permanente l'étouffait. Il restait pendant des heures immobile, ou bien il éclatait en larmes [...] (Págs. 116-117).

Algo más adelante en la novela - Arnoux habla:

-Il faut cependant que jaille embrasser ma femme.

"Ah! sa femme!" pensa Frédéric.

Puis il se coucha, avec un douleur intolétable à l'occiput; et il but une carafe d'eau, pour calmer sa soif. (Pág. 199).

Las reacciones espontáneas miedo-coraje y aversión-odio y el resorte que las une a los impulsos es lo que más falta -o se encuentra disminuido- en este tipo. Asi, los odios resultan enclenques: Barrios lo manifiesta expresamente de Luis - "no era él capaz de sustentar tenaces rencores" (I, r 20) - - y Sacha de El mundo es ansí dice lo mismo de Arcelu -_en el fondo, Arcelu debe ser un hombre sin energía para odiar" (pág. 
I23) - Frédéric hasta cree sentir simpatía por el marido de la mujer que ama: "il fut pris de tendresse pour cet homme intelligent et bon, que ses amis calomniaient et qui maintenant travaillait tout seul, abandonné. Il ne résista pas au singulier besoin de le revoir immédiatement" (pág. 78).

El odio es otras veces la herida en el amor y el entretenerse en escarbar en la herida, en lo oscuro del alma. "¡Oh, cuánto odio! Ese pobre odio del despecho, tan emparentado con el amor" llena a Luis cuando se encuentra con Teresa después de la revelación de la infidelidad, de la pelea con Rojas, pero esa misma pasión pierde contacto con la realidad y se escapa por figuraciones de venganza y fantasías sadistas más vivas que la realidad misma vivida por Lucho (II, 238). Las páginas que quedan del capítulo son de lo mejor en novela que se ha escrito en español -en medio de aquellas imaginaciones comienza a mezclarse o a salir a la superficie el deseo sexual; un rato más tarde Lucho ama, entrega, perdona.

Frédéric hace gala de una temeridad que más que coraje o valentía -que presuponen el miedo-parece un embotamiento o desconección entre los estímulos y lo circunstante. En medio de la rebelión en París, en medio de la batalla misma, "il lui semblait assister à un spectacle" (pág. 42I); acaba de pisar a un muerto, arrecian las descargas de fusilería, mas él se pone a considerar las circunstancias secundarias, como los combatientes que alternan la lucha con la bebida o un perro perdido que aúlla - "cela faisait rire" (pág.422)..$^{15}$

Claro es que se trata de una cuestión de grado: hay en cada sujeto un punto de intensidad en que la emoción puede absorber totalmente la siquis, y entonces puede hacer desaparecer toda división o quiebra en las facultades o potencias anímicas del más complejo o refracto de los hombres y mover espontáneamente los impulsos para la acción: $\mathrm{El}$ adjetivo "devoradora" aplicado tantas veces a la pasión erótica intensa expresa muy bien este poder de la. pasión suficientemente fuerte -en Strindberg podrán hallarse ejemplos que caigan a la medida; el siempre irresoluto Luis se encuentra a sí mismo en los labios carnosos y elásticos de Teresa, "que parecían succionar y encender las entrañas. Una descarga erótica reforriale la médula entonces, y le hacía crepitar los nervios como electrizados, galopar la sangre, gemir de deseo los músculos enflaquecidos ya" (II, I9I). ${ }^{16}$

15 Este valor falso - "faux courages"- - ha sido observado en relación al mis. mo episodio por Philibert de Lastic (La Patbologie mentale dans les Oeuvres de Gustave Flaubert [Paris, 1906], 66-67).

16 En Nueva York, 1951, se puhlicó como traducción de una nueva obra póstuma de Nietzsche el libro que lleva el título de $M y$ Sister and $I$, y a continuación 
Las mismas pasiones de lo irascible, de las que afirmamos hace un momento que aparecen como las más flacas - o desconectadas-en este tipo, llegado el caso hacen desaparecer todo actor o espectador y se conec. tan sin intermediario a los impulsos - el mejor ejemplo es el miedo, que puede borrar toda sicología fuera del correr de las piernas. A continuación del último episodio a que nos referimos en L'éducation sentimentale parece insinuarse una reacción de esta clase-coraje-: "Frédéric fut ébranlé par le choc d'un homme qui, une balle dans les reins, tomba sur son épaule, en râlant. A ce coup, dirigé peut-être contre lui, il se sentit furieux; et il se jetait en avant quand un garde national l'arrêta. - C'est inutile! le Roi vient de partir" (págs. 422-423). En la vida de Luis se da plenamente un solo estallido pasional espontáneo-cólera en este caso-, puesto en su punto por mano maestra: la pelea, ciego de ira, con el compañero de oficina (II, 234-235).

A veces las pasiones que no se comunican naturalmente a los impulsos más la conciencia que se vuelve con intensidad creciente sobre el sujeto mismo acaban por producir un desquicio poco menos que total de las percepciones, de la ideación y la motilidad - como cuando el muchacho de once años se deja invadir por la timidez primero, que progresa pasiva. mente hasta que parece desbordarse histéricamente $(I, 46)$; luego la imaginación se escapa para volver de nuevo a escarbar. Al fin

ya no vio, ni sintió, ni oyó nada. ¿Cómo anduvo las calles?... Sí, sí oyó, sí vio, sí percibió muchas sensaciones. Aunque al día siguiente no las recordase ya. ¿No? ¿Había olvidado? Tampoco. No habia olvidado, precisamente. Olvida el cerebro; la sensibilidad, nunca. Interrogándola, hubiera encontrado en esta memoria más pura, ${ }^{17}$ si no los hechos mismos, recuerdos

su autenticidad fue puesta en tela de juicio. El autor de dicho libro, quienquiera que sea, ha tenido bastante talento - y parecida experiencia o penetración sicológica- para describir el efecto unificador de la pasión intensa en una siquis en extremo refracta, que provoca expresiones extrañamente parecidas a las de la experiencia de Lucho y a otros testimonios que traeremos más adelante: "This Dionysian mystery which I had grasped only in philosophic theory, was made factual to me when a mere word or gesture from Lou was enough to set the springs of my erotic being into action. And instead of heing outside my body like an actor [no está en bastardilla en el original] pushing his disguised self across a stage and directing its movements like a puppet-master [idem], I was inside my body [...]" (pág. 249).

17 Esta es una palahra que en este lugar resulta muy significativa de que Barrios tiene en cuenta la importancia de las notas de dividido o simple en la consideración del carácter. Estas señales se encuentran abundantemente en Barrios ( y a veces pueden no ser repensadas); otro ejemplo es la palabra "entero" en la cita de la nota ${ }^{7}$, que no significa alli íntegro, ni recto, ni terco, y que como nota relacionada con "varonil" creemos que proviene de la intuición de los tipos (lo cual quedará aún más claro al estudiar la relación tipo-sexo y el interés de Barrios en lo sicológico). 
esenciales a los que la imaginación habría construido episodios equivalentes. Pero a él bastábale la esencia. De golpe había experimentado primero la absoluta imposibilidad de escapar al trance, y se había entregado a él sumiso. Después, un tumulto obscuro de cosas confusas en el corazón oprimido, una angustia en el estómago, una laxitud en las coyunturas, un hielo en las venas..., y caras [aquí la sinécdoque no está en la expresión, sino en la percepción misma] que asoman por puertas y ventanas y se ríen, y los bultos de la familia que va con él, y el olor antipático a género nuevo de su disfraz, y ojos..., más bien miradas, flúidos que se hunden en su carne... ¿Qué más?... Un sentirse desarraigar de la vida, suspender en el vacío... Luego la conciencia de que iba de la mano de papá Juan. $(I, 48)$.

Y el muchachito empieza a despertarse, a recobrarse de la crisis.

\section{EL TIPO Y LA CREACIÓN LITERARIA}

Aun a riesgo de que suene demasiado categótico, vamos a usar un enunciado axiomático como punto de partida para llegar a una conclusión aplicable a nuestro caso: lo compuesto presupone lo simple; lo simple es... lo simple. En términos sicológicos, lo compuesto conoce lo simple, mas lo simple no conoce lo compuesto. Fausto podría escribir su propia tragedia e inclusive concebir la simplicidad y grandeza de Gretchen, mas ésta, por muy alto que subiera, no podría hacer otro tanto con la complejidad de Fausto. Otra ilustración más cercana: Luis Murguía o José Ignacio Arcelu, si supieran escribir novelas, podrían crear un Zalacaín; Zalacaín jamás podría crear un Murguía o un Arcelu.

Para conocer, crear un Luis Bernales, hay que tener algo en común con Luis Bernales - no sus logros y fracasos en la vida, en el carácter, no las circunstancias o episodios semejantes en el medio familiar o social, ${ }^{18}$ pero sí una cierta cantidad de refracción sicológica. ${ }^{19}$

18 Es por demás simplista partir de coincidencias de esta clase (que el autor puede además recomponer, alterar a su antojo o al de sus personajes) para encontrar un parentesco sicológico entre un protagonista y su autor. Está plenamente justificado Bartios cuando afirma (citado por Hamilton): "No soy yo, por supuesto, ese Lucho Bernales. Algunos han dado en suponer que Un perdido es novela autobiográfica. Falso". (Artíc. cit., pág. 283).

19 Las investigaciones en sicología y siquiatría - trabajos con un método tan distante como Sex and Personality de Terman-Miles, y el que aquí citamos de Kretschmer, por ejemplo- llevan a concebir la distribución de los tipos no como polos alejados uno de otro sino como un meridiano a lo largo del cual se dan distintos acercamientos a las orientaciones extremas. Kretschmer habla de la "Psychästhesie der gesunden Durchschnittsmenschen gemischten, mittleren Temperaments" (pág. 139 - la sicoestesia del hombre sano común con un temperamento mixto, medio). 
Esto se ve corroborado cuando el autor usa a un personaje para expresar algunos de sus juicios o pana poner las cosas en su punto con relación a los demás protagonistas de la novela, y este personaje - que en cierto modo se apropia del autor- muestra un carácter estructurado en la manera que hemos dado en llamar REFrACTA. Tal es, en Un perdido, el caso del teniente Blanco. En Blanco siempre asoma la autocrítica en el origen mismo de sus actos y juicios tanto como el prurito moralizante para los ajenos ${ }^{20}$ - cierto es que sus consejos a Lucho durante el período de Iquique son de los aprovechables, producto de una personalidad madura.

Más adelante Robles casi lo único que hace -él que no puede arreglar su propia vida - es criticar y aconsejar a Luis; aunque no anda desacertado en las opiniones, se fija constantemente en las fallas del otro y muestra un excesivo metimiento que hace que Luis se resienta de tales "franquezas" (II, 209, 21 2, 225, etc.). Este frecuente enjuiciar a los demás aparece también en Frédéric Moreau; una palabra o dos bastan, en el estilo de Flaubert, para revelarlo: "Cependant, on apercevait sur sa mine [de Rosanette] un effort, une intention de respect; et, comme cet air sérieux la rendait plus jolie, Frédéric l'excusa" (pág. 469). Otro ejemplo: "Frédéric s'en alla. L'ineptie de cette fille, se dévoilant tout à coup dans un langage populacier, le dégoûtait" (pág. 453) - se trata de Rosanette, muchacha llena de personalidad, de quien se ha sentido enamorado en más de un momento. Con Louise Roque, quien está perdidamente enamorada de él, se hace el que no entiende sus giros populares: "il feignit de ne pas comprendre ce mot de patois, et même la taquina sur son accent" (pág. 372). ${ }^{21}$ No se trata de la burla espontánea dirigida a lo diferente de lo común, a lo que se aparta de lo convencional o socialmente aceptado, sino de la burla pedante.

Volvamos a Blanco. El lenguaje mismo de este personaje revela la autocrítica de que hablamos, más el prurito de exactitud y la tendencia a la generalización $e$ inseguridad resultantes - abundan las expresiones como "tal vez", "acaso", "puede ser", etc. Nada mejor que leer el largo análisis que Blanco hace del padre de Luis - que además lleva la intención

20 En el sistema de Kretschmer esta tendencia puede aplicarse al esquizotímico por oposición a lo que afirma del ciclotímico, que carece de toda veleidad moralizadora (pág. 123, final del primer párrafo). Kretschmer apunta varias veces a la tendencia al pedantismo en el esquizotímico-por ejemplo, en págs. 151, 154.

21 Según Kretschmer basta esta actitud para clasificar a un sujeto: "Die Neigung zum korrekten Hochdeutschsprechen in einem nicht so sprechenden Milieu kann manchmal direkt eine schizoide oder schizothyme Anlage verraten" (pág. 143 - la tendencia a usar un correcto alto-alemán en un medio donde se habla más vulgarmente, puede a veces traicionar [descubrir] inmediatamente una disposición esquizoide o esquizotímica). 
aleccionadora dirigida a Luis (y que resulta por demás sicológico para tema del común de la gente, aun gente culta) - (las palabras subrayadas no lo están en el original): "Puede ser la suya una de esas timideces invencibles. Acaso sea más tímido aún que tú. Puedétambién que sea un poco menos afectivo" (I, I24). Las palabras dubitativas - y perfeccionistas a la vez- se hacen hábito hasta el punto de que brotan en frases en las que carecen de sentido o significado como no sea el de descubrir que están siempre en el espíritu del personaje (y del autor en este caso) y que se le escapan solas. En el largo párrafo de Blanco que da el sentido a la novela nos encontramos con un ejemplo (el subrayado es nuestro): "Y a nadie le falta un amigo así, que fue bueno, serio, simpático, decentísimo; a quien supusimos ver más arriba que muchos imbéciles que luego son personajes, y a quien años adelante descubrimos, sin embargo, en completo abandono, dando tumbos, cabizbajo, embrutecido, tal vez fango en el fango. ¿Cómo rodaron? Es lo que nos preguntamos, sin concebir una precisa respuesta. Y algún secreto habrá, pues que rodaron" (II, 3II). Otro, del autor: "Despertaba en su corazón una angustia algo inquietante $[\ldots]$ " $(\mathrm{I}, 43)$.

Puede sonar contradictorio esto de que el tipo que parte de una inseguridad básica sea el mismo que dicta los principios a los demás. Es claro que estamos hablando no de un caso más o menos limitado - como el del "perdido" o cualquier otro- sino de un gran tipo de la personalidad (Kretschmer para su tipología, en un párrafo en que expresa sus dudas y lo difícil del tema, usa el término "der grosse schizothyme Konstitutionstypus" [pág. 156]) que se da en una escala que va desde los "desechos humanos" hasta las cumbres intelectuales y morales. No todas las actitudes complejas, reflexivas, críticas o moralizantes producen frutos parecidos, pero la actitud que hace que ciertas personas se hagan de algún modo un problema de la propia y la ajena sicología —es decir, que puedan llegar a fijarse en los demás de un especial modo analítico-, que constantemente formulen juicios, generalicen ${ }^{22}$ es típica y tiene que ver con algunas de las facultades necesarias al autor de sicología literaria y de la otra.

22 Kretschmer se refiere en varios lugares a la tendencia lógica, esquematizadora, sistematizadora, generalizante, del esquizotímico, tanto en la siquis anormal (pág. 143, 1er. párrafo) como en hombres superiores (pág. 152, arriba). Esto se acerca a lo que tantas veces se observa en escritores y hombres de genio, que bajo las apariencias del amor a una mujer, aman en realidad a la mujer, lo absoluto - todo a uno con la religión, el arte-; Kretschmer lo menciona de los semilocos (y lo repite más tarde al hablar de los esquizotímicos geniales): "Man sucht nicht ein Hübsches Mädchen, sondern 'das Weib', das 'Absolute', Weib und Religion und Kunst in einer einzigen Gestalt" (pág. 144). 
Barrios da a su personaje Lucho, desde una precoz adolescencia, este ințerés ingenuo en las sicologias - y nos parece que el elemento de incli. nación a analizar a los otros está relacionado con la experiencia del propio autor-; la angustia, la curiosidad del muchachito que se despertaba prematuramente "exigíale a la vez explicarse un poco los hombres y sus actos. En su derredor veía gesticular a unas cuantas personas - niños en su mayoría, pero también adultos- $[\ldots]$ Poco a poco, el observar a los 'demás, tratando de comprenderlos, llegó a consumir muchos de los momentos de blanda holganza $[\ldots]$ " $(I, 43)$.

Nietzsche, uno de los autores predilectos de Barrios, cuya obra contiene muchas alusiones o referencias directas a la dualidad en su propia siquis o "naturaleza", ${ }^{23}$ nos ha dejado una frase que envuelve o implica estos distintos aspectos de un solo tipo básico de organización —el raciocinio que sustituye al impulso, lo deliberado a lo espontáneo, principios en lugar de hábitos (y la tendencia a generalizar conexa), la autocrítica y la capacidad consiguiente de perfeccionamiento y de ver los errores en la obra propia, ${ }^{24}$ el prurito moralizante (también Nietzsche), los extremos de tenacidad férrea (constante gobierno de lo consciente-intelectual sobre la volición, que cubre un vacío "abúlico") ${ }^{25}$ - y su relación con la aptitud

23 En la primera página de Ecce Homo: "ich kenne Beides, ich bin Beides"; cuatro páginas más adelante: "Diese doppelte Reihe von Erfahrungen, diese Zugänglichkeit zu anscheinend getrennten Welten wiederholt sich in meiner Natur in jeder Hinsicht, - ich bin ein Doppelgänger, ich habe auch das 'zweite' Gesicht noch ausser dem ersten"; y aún más: "Und vielleicht auch noch das dritte..." ("Warum ich so weise bin", 3) - sigue la traducción, desde la primera cita: Conozco ambos lados, porque soy ambos lados. Este doble hilo de experiencias, este medio de acceso a dos mundos que parecen tan separados el uno del otro, tiene en cada detalle su réplica en mi propia naturaleza- yo soy el complemento de mí mismo: tengo una segunda vista, tanto como una primera. $Y$ quizá también tengo una tercera vista...

24 La tendencia a lo selecto que Kretschmer señala en el esquizotímico (págs. 143, 144 y pág. 153: "Feinsinn und Stil ist auf der einen [los esquizotímicos]" - refinamiento y estilo corresponde a los esquizotímicos-) está relacionada a este aspecto; Nietzsche lo avala con su testimonio autobiográfico, "er ist ein auswählendes Princip" ("Warum ich so weise bin", 2. -él es un principio selectivo-). Baroja, hablando de sí mismo, nos descubre el papel que un carácter refracto puede desempeñar en el allanamiento de las defensas opuestas pot el egoísmo simple (o primatio) que no permite confesarse las propias faltas - la neutralización de ese egoísmo es la primera condición para el proceso de perfeccionamiento en este tipo: "Yo pienso que puedo hablar de mí mismo sin sentir ningún entusiasmo egotista, físico o intelectual. Me figuro que puedo desdoblarme en un actor y en un espectador, en un actor a quien puedo juzgar, naturalmente, con cierta benevolencia, de padre a hijo" (Prólogo de El escritor según él y según los criticos, Obras completas, VII, 389).

${ }_{25}$ Kretcshmer se refiere a esta fuerza de voluntad consciente y pertinaz de algunos esquizotímicos escogidos, en una comparación con el tipo opuesto: "Deshalb finden wir bei den Zykloiden allenthalben viel warme Arbeitsfreude, flüssige, praktische Energie, aber wir finden bei inhen nicht in erster Linie die harte, 
para crear personajes y la creación literaria en general: "Meine Humanität ist eine beständige Selbstüberwindung". ${ }^{26}$ Las mismas palabras podrían finalizar el Secretum del Petrarca, las páginas autobiográficas de Goethe... -en ellas se contiene la empeñosa, obstinada lucha del genio.

Queda algo que observar en Blanco que es especialmente significativo para situarlo en su tipo y que nos llevará a una mayor penetración ên la sicología de la creación literaria. El teniente tiene un compromiso con unas tiples de zarzuela y lo deja de lado para disolverse en la contem. plación del mar. Lo hace deliberada y conscientemente, como todo en este tipo, como en una constante pugna moral - "tenía compromiso", "sin embargo", "yo hice bien" (I, 225 226). Luis - sólo por el mismo carácter pedagógico pues él no es muy de no faltar a compromisos- le observa al otro "¿qué van a pensar de usted?" Blanco "cierra los párpados como para recoger su mirada y con ella su espíritu disuelto un instante en aquella dulzura", y a continuación raciocina: "Hay una gran belleza que nos reconcilia con nosotros mismos cuando faltamos a cualquier compromiso por ceder al precioso deseo de un instante". Pongamos aquí el amor a la naturaleza en los que Kretschmer llama esquizoides o esquizotímicos:

Entspringt die Natur- und Bücherfreundschaft zykloider Naturen, da wo sie auftritt, einer gleichmässigen Liebe zu allem, was ist, nämlich zuerst zu den Menschen, dann auch zu den Dingen, zo zeigt die Interessensphäre schizoider Menschen nicht diese gleichmässige Affektbesetzung. Schizoide Menschen, auch einfacher Herkunft, sind überaus häufig Natur- und Bücherfreunde, und sie sind es mit einer gewissen elektiven Betonung. Sie sind es aus Flucht vor den Menschen und aus Hinneigung zu allem, was still ist und nicht weh tut. Bei manchen hat diese Hinneigung etwas direkt Kompensatorisches. Alle reizsame Zärtlichkeit, deren sie fähig sind, und

zielfeste, unheugsam bis zum Ende durchgreifende Tatkraft gwisser schizoider Temperamente" (pág. 123-por eso encontramos por todas partes entre los cicloides mucho calor por el trabajo, una enetgía práctica e ininterrumpida, pero no encontramos entre ellos en lo más mínimo la rigurosa, perseverante en la mira, inflexible hasta el fin, eficaz y decisiva energía de ciertos temperamentos esquizoides). El siquiatra de Marburgo vuelve sobre este rasgo de los esquizótímicos dotados, en las líneas finales de "Die soziale Einstellung" (pág. 145), en las que se refiere a su tenaz lucha por su ideal; más adelante repite su observación de este rasgo, en varias oportunidades.

${ }_{26}$ "Warum ich so weise hin", 8. -Mi humanidad es un constante proceso de dominio de mí mismo. Esta misma idea se halla implícita en el desarrollo anterior, bajo el número 2 del mismo libro, en el que alternan expresiones que podrían ser síntoma de megalomanía, con revelaciones geniales. Kretschmer sitúa a Nietzsche en el tipo (pág. 212 últ. línea y 213) junto con Heine y Voltaire; para la relación entre su enfermedad y su sicología, ver el estudio "Nietzsche. Maladie, Orgueil et Génie" de Georges Codino, en Nietzsche. Etudes et Témoignages du Cinquentenaive, Société Française D'Études Nietszcheennes, 1950, 83. Codino señala a la etiología infecciosa de la locura (parálisis) de Nietzsche y niega por tanto que sea una evolución o acentuación de rasgos de su sicología normal. 
die die Menschen zurückstossen, wird verschwenderisch über die schöne, stille Natur und die toten Sammlergegenstände ausgeschüttet. ${ }^{27}$

Traigamos el testimonio de Nietzsche: "Er ist immer in seiner Gesellschaft, ob er mit Büchern, Menschen oder Landschaften verkehrt" (Ecce bomo, ibid., 2); "T... T ich habe Einsamkeit nöthig, will sagen, Genesung, Rückkehr zu mir, den Athem einer freien leichten spielenden Luft. . Mein ganzer Zarathustra ist ein Dithyrambus auf die Einsamkeit 「... (Ecce bomo, ibid., 8). "Der Einsame sprikbt. - Man erntet als. Lohn für vielen Ueberdruss Missmuth Langeweile - wie diess alles eine Einsamkeit ohne Freunde Bücher Pflichten Leidenschaften mit sich bringen muss - jene Viettelstunden tiefster Einkehr in sich und die Natur" (Der Wanderer und sein Scbatten, núm. 200). ${ }^{28}$

La huida de los hombres que está en la base de esta actitud aparece frecuentemente en Luis. Cuando sorprende una confidencia de su padre con el coronel del regimiento por la que se da cuenta de que también su padre sufre como él, en lugar de abrírsele el corazón, se siente "aplanado", con una flojedad mortal, "como si le hubiesen vaciado las venas". 29 Se dirige sigilosamente a su cuarto; cierra la puerta con llave. "Diríase que necesitaba defender su soledad $[\ldots]$ " (I, I22). Más adelante en la novela se acentúa el derecho que tendríamos a refugiarnos en la soledad

27 Págs. 142-143. Sigue la traducción: Mientras que los amigos de los libros y la naturaleza de personalidad cicloide, cuando se dan, se originan de su amor a todas las cosas por igual, es decir, primero a los humanos, después también a las cosas, la esfera de intereses de los esquizoides no muestra este equilibrio emocional. Los esquizoides, aun los de baja extracción social, son con frecuencia amigos de la naturaleza y de los libros, y lo son de una manera claramente deliberada. Lo son por un escape de los hombres y por su inclinación hacia lo inofensivo. En muchos esta inclinación recibe una directa compensación: toda la excitable sensibilidad de que son capaces, con la cual rechazan a los hombres, se vierte pródigamente en la pacífica naturaleza y en los objetos muertos de los coleccionistas.

28 El está siempre consigo mismo, ya su trato sea con los libros, ya con los hombres, ya con el paisaje de la naturaleza. -Necesito la soledad, es decir, restablecimiento, reencontrarme conmigo mismo, llenarme los pulmones con el libre, tónico, refrescante aire. : . Todo mi Zaratustra es un ditirambo a la soledad. -El solitario habla: en compensación por mucho disgusto, descorazonamiento, aburrimiento que deben resultar de una vida aislada sin amigos, libros, obligaciones y pasiones, gozamos de esos breves lapsos de profunda comunión con nosotros mismos y la Naturaleza.

29 En todo este estudio se aplica lo que ya dijimos en el texto $-\mathrm{y}$ se desprende de las notas $\mathbf{1 3}$ y 19 _, que en el tipo humano que nos ocupa se produce toda una gama, en la que hallamos sicologías logradas y sicologías enfermas; a menudo estudiamos la siquis normal y saltamos luego a manifestaciones anormales que son como una exageración o desorganización de los mismos rasgos normales, lo cual no significa que se desconozca la diferencia entre salud y enfermedad. En esto seguimos la actitud y sentir corrientes en la siquiatría actual, que se encuentra también en Kretschmer. 
de nuestro yo interior, opuesta a la soledad o indiferencia exterior con que otros nos hieren - "ni siquiera nos deja el extremo refugio en un sereno yo interior" (II, 70)-, y todo el pasaje revela esa vehemente apetencia de ternura que no encuentra canales por donde comunicarse a los otros y que - como en este caso- tampoco encuentra correspondencia en los otros. Algunas palabras de Barrios parecen encontrar ecos en la bella cita de Kretschmer: "sie schliessen die Läden ihres Hauses. um in dem zarten, gedämpften Halbdunkel ihres Innern ein phantastisch tatenarmes und gedankenvolles' (Hölderlin) Traumleben zu führen. Sie suchen, wie Strindberg so shön von sich sagt, die Einsamkeit, um sich 'in die Seide ihrer eigenen Seele einzuspinnen" ". ${ }^{30}$

Cuando esta soledad se encuentra frente a la soledad de la naturaleza, y si hay un caudal suficiente de amor en el sujeto-pasión e impotencia para darle salida -, ese amor se revierte en las cosas y se expresa en un misticismo cósmico - la "profunda comunión" de que nos habla Nietzsche. ¿Tiene Lucho Bernales el ardor y el genio necesario para una experiencia de este orden? En nuestra novela -una de dos-lo tiene por derecho propio de personaje o lo roba (lo cual es más probable) del genio de su autor, en el bellísimo pasaje en que contempla el cielo y el mar, desde la popa del barco que había traído a la compañía de zarzuela:

Y entonces; como el ojo de Dios en las viejas estampas del teólogo, asoma por un desgarro de la bruma la roja pupila del sol; tiende unos instantes su mirada, abanico de flechas encendidas, sobre la solemnidad de la alta mar, y desaparece de nuevo.

En Luis ha ido perdiéndose la personalidad. La dominación que ejercen los tornátiles aspectos de la luz le ha ido diluyendo el alma en el ambiente. Ya no es él, es una nota tremolante de la inmensidad encantada $[\ldots]]^{31}$

\section{EL TIPO ESPONTÁNEO}

Cuando dejamos a los personajes de estructura compleja de la personalidad - los REFRACTOS-, con su genio o sus fracasos, sus reflexiones y

30 Pág. 141. Cierran los postigos de su casa para llevar su pensativa vida de sueños, "inactivos y meditabundos" (Hölderlin), en la tenue y amortiguada media luz [crepúsculo] de su interior. Tal como tan bellamente Strindberg lo dice de sí mismo, buscan la soledad a fin de "entollarse en la seda de su propia alma".

31 Por supuesto, también hay aquí arte (o intuición literaria) en que el contenido de la comparación y de la metáfora subsiguiente prepara al lector a participar en una unión de tipo místico con la naturaleza. A esta altura estará más claro que es por este rumbo por donde podremos descubrir al autor en su obra y no en la cruda ecuación Barrios = Lucho Bernales. 
raciocinio y vacilaciones, su constante conciencia de actos y juicios, de sí mismos y de los demás, y dirigimos la atención al tipo opuesto, experimentamos de inmediato algo como aligeramiento, como un soplo de aire fresco, de salud o de normalidad síquica. Es la virtud de lo simple.

Hay una frase de Kretschmer que resume este aspecto del contraste entre los dos tipos de personalidad -está hablando de los "esquizoides"--: "Alles in allem: es fehlt auch bei Betrachtung der engeren Psychomotilität wieder am unmittelbaren Zusammenarbeiten der beteiligten Instanzen zwischen Reiz und Reaktion. Es fehlt das, was die Zykloident so ausgesprochen besitzen: das Runde, Natürliche, Ungezwungene im Affektausdruck und Bewegungsakt". ${ }^{22}$ Los mismos refractos suelen sufrir un complejo de inferioridad típico-que Arcelu pone en palabras de comicidad amarga inconfundiblemente barojiana: "Yo soy como esos animales mal construidos que parece que alguno los ha hecho por entretenimiento" (pág. I28). Una actitud de superioridad como la de Nietzsche tiene la misma duda de sí mismo en la base, y a veces la duda es manifiesta, como cuando trata de encontrar pruebas de que no es un decadente (Ecce bomo, "Warum ich so Weise bin", 2, pág. I). A lo largo del libro de Barrios puede anotarse ese complejo de inferioridad en Lucho; por ejemplo, cuando en el baile infantil piensa una réplica oportuna que "le reconcilia consigo mismo" ( $I, 50)$, o cuando admira o envidia a Anselmo - "el propio Luis llegó a envidiarlo" (II, 50).

El abuelo de Lucho, por otra parte, nos da la interpretación del tipo simple hecha por el refracto - su versión-: "Al fin y al cabo, en muchos casos, la confianza y el aplomo no son más que una suspensión de la conciencia" ${ }^{3 *}$ Otras referencias, aunque aluden al elemento de simpatía, señalan al mismo tiempo a las limitaciones del espontáneo: Anselmo "era el mismo muchachote alegre, tarambana, despreocupado y egoistón" (II, 49); "Rojitas $[\ldots]$ sería egoísta $\mathrm{e}$ insubstancial, mas no intruso [intruso = amigo de moralizar a los demás], y sí alegre, comunicador de su liviandad, benéfico al ánimo..." (II, 2 I 3$).{ }^{34}$

32 Págs. 146-147. Traducción: De nuevo le falta [al esquizotímico], al examen de su contraída sicomotilidad, la inmediata sinergia de las instancias simultáneas que unen la excitación y la reacción. Le falta lo que el cicloide posee sin duda alguna: lo integrado, lo natural, lo espontáneo en la expresión de la pasión y los movimientos.

${ }_{33}$ I, 48. El subrayado no pertenece al texto: esta palabra también merece consideración especial; no se trata de la conciencia moral sino de la conciencia, consideración, juicio sohre los propios actos - dicha por el abuelo se tiñe de sus otras acepciones favorables al nieto.

34 . Este egoísmo del espontáneo (ver nota ${ }^{24}$ sobre su neutralización en el refracto) consiste en la lealtad básica, esencial, que empieza por casa y se ejerce 
Aplomo en lugar de duda. El carácter espontáneo no se complica la existencia buscando razones pata lo que quiere, ni necesita razones o prin. cipios cuando quiere. Lucho lo observa en Teresa: "Caviló en reserva toda la tarde, intrigado por aquella muchacha que abandonaba el hogar paterno para lanzarse 'porque sí' a una capital desconocida y sin dar otra explicaçión que la de no poder seguir con su familia "porque no" "(II, I72). La primera observación sobre su carácter, al primer encuentro: "De pronto ella, cual si hubiese reposado lo bastante, miró en redondo, y midiendo primero a Lucho de pies a cabeza le preguntó con naturalidad y aplomo: - ¿Podría decirme la hora, señor?" (II, I67-I68). Más adelante a Teresa le atrae la idea de tener dinero, y a una interpelación de Lucho, contesta: "Sí, claro. Lo digo porque..., en fin, porque se me ocurre y nada más" (II, I90).

Del mismo modo como no se complica la existencia, este carácter no comprende que los otros puedan complicársela, de manera que sólo atiende a lo exterior de las complejidades del otro tipo y por tanto las ve ridículas. Teresa tilda de "ridículo 'tanto sentimentalismo y tanta ñoñería" ", cuando Robles se desahoga del enojo debido a que su hermana entra de monja (II, 206) -eesto es lo que muchas veces se llama, en el consenso popular,

después con los demás -y que jamás se anula en el espontáneo, como todo en este tipo. Kretschmer lo ve en su cicloide en los siguientes términos: "ein fast drolliges UUberzeugtsein von dem Wert und den Rechten der eigenen Individualität" (pág. 123 - una cuasi cómica convicción del valor y de los derechos de la propia individualidad); al comienzo del mismo párrafo en la página anterior se refiere a la característica puerilmente ingenua de esta clase de egoísmo, que se compensa con la inclinación a darse a los otros y simpatizar -esto último lo veremos en seguida en nuestros personajes de Un perdido. Nuestra afirmación de que consiste en la lealtad a sí mismo, jamás claudicante en este tipo, se confirma si recordamos que el espontáneo nunca se aviene a reconocer sus propias fallas aunque es al mismo tiempo sencillo (= espontáneo) y tolerante ("no intruso", etc.) - Kretschmer apunta a la modestia del ciclotímico que lo hace especialmente agradable (pág. 123, final del primer párrafo), a su avenimiento a compromisos y transacciones (párrafo siguiente), y a su carácter moderado, complaciente e indulgente (pág. 125, último párrafo de la sección); el hombre común espontáneo*es más o menos "educado", más o menos "egoísta", según haya aprendido a reconocer más o menos la misma lealtad básica de los otros. Al tomar otra vez el hilo de la nota 24 en dirección al tipo refracto, observemos cómo su capacidad de autocrítica no excluye los complejos inferioridad-superioridad -paradójicamente la autocrítica y la modestia convencional nunca andan juntas-; clato es que en un hombre superior de tendencia refracta puede darse una valoración exacta de sí mismo, en el modo de desprendimiento que distingue a este tipo y que se ejemplifica en la cita de Baroja - esto por sí solo no constituye orgullo, y menos egoísmo, aunque generalmente es mal interpretado por la mayoría, que no concibe y por tanto no se da cuenta de ese desprendimiento sobre la propia persona-; el egoísmo en el refracto se encuentra en una zona diferente - es la prescindencia, o no consideración, o falta de interés por y en los demás (o falta de un interés genuino, espontáneo, que puede observarse en sus relaciones sociales, nota 13 última parte), en mayor 0 menot grado. 
sentido común. Anselmo se ríe de "las ridiculeces de lo que él llamaba 'tragicómico adolescente" "35 — se trata de una situación diferente de la anterior pero la actitud mental es la misma.

Este carácter espontáneo tiene siempre primero en cuenta lo práctico y no se descuida de lo social -esto último por su natural comunicativo tanto como por lo anterior, el interés práctico, el saber lo que le conviene. "La vida se ha hecho para disfrutarla", dice Teresa. "Hay que rodearse un poco de gente. Lo demás es enfrascarse, apolillarse". ${ }^{36}$ Cuando el tipo espontáneo se da en un temperamento vivo, animado, su carácter comunicativo se contagia a los circunstantes; de esta pasta son los animadores más apreciados de reuniones, los simpáticos por excelencia; a ellos corresponde el éxito social -así Anselmo con las chicas a la vuelta de sus viajes, así Rojitas en el círculo de los amigos de Lucho y Teresa. Este éxito no depende en primer lugar de la originalidad y el ingenio sino de lo comunicativo, lo cálido, lo personal en las relaciones del espontáneo; mientras que el otro tipo, refractario al hábito, se devana los sesos para inventar bromas o respuestas agudas - que en muchos casos no llegan a tiempo-, las concurrencias rápidas e infaltables del espontáneo aciertan por aproximación y son casi siempre frases hechas, lugares comunes, clichés sociales que cobran precisión y sinceridad-vida-por el gesto oportuno, la intención y la vivacidad - aquí como en otras manifestaciones, su personalidad necesita el apoyo del trato con los demás.

Teresa trata de estimular a Lucho con el ejemplo de Rojitas - que en este caso de tipos extremos es tanto como pedirle a un lirio que dé ro. sas-: "Ves, Lucho, cómo se necesita de algún trato con la gente?". "Si, tienes razón", contesta Lucho, haciendo honor al sentido práctico en el

35 II, 137. Es propio del carácter de Anselmo reírse del "tragicómico adolescente", no así definirlo con un nombre que revela interés o formación literaria y sicologizante no común en un muchacho. Este es otro ejemplo del interés de Barrios mismo en la sicología.

36 II, 192. Observar cómo la personalidad del autor se vende en un personaje -aun de tipo opuesto-. La repetición "enfrascarse, apolillarse" revela la búsqueda de exactitud en la mente del autor - a quien le gustan las dos palabrastanto como un rasgo de indecisión; en boca de Teresa hubiera sonado más natural sólo una de los dos. Esta observación y la de la nota anterior nos hacen ver cómo es más difícil para un autor dibujar los personajes de un tipo sicológico opuesto al propio. En realidad Barrios se distingue de la mayoría de los autores en que rara vez se descuida del detalle sicológico y de este modo sus personajes de tipo opuesto no caen en el vicio común de ponerse a hablar como el autor. No desarrollaremos comparativamente este punto, que en cuanto a Barrios ya se desprende de los ejemplos incluidos en este ensayo. El lector que se interese podrá encontrar repetidas muestras de este hablar como el autor en algunas de las mismas novelas que compararemos más adelante - Thomas Mann, Faulkner, Barcia-; Flaubert es exacto en el detalle sicológico, pero apenas si trata a sus pocos personajes de tipo opuesto. 
consejo de Teresa. "Y en esto y en todo, Lucho concluía por dar la razón siempre a su querida" (II, I94-195). Rojitas también aporta su grano de sentido común a las situaciones, como cuando "Lucho sintió como una coz en el corazón. Ahí estaba la 'franqueza' sobre la carne viva [los impertinentes - aunque acertados-consejos de Robles]. Un guiño de Rojitas le devolvió el buen sentido. - Le hierven los jugos. No le hagas caso. Si todos los muchachos que se gastan una hembrita por ahí fueran a razonar como economistas..." (II, 209). Estos - los de Teresa, de Rojitas - son los consejos de los espontáneos; "te conviene esto, o lo otro", "no te hagas mala sangre", "nadie se dará cuenta", entre los que pueden darse excelentes ejemplos de sabiduría práctica. Nunca muestran el prurito moralizante, pedagogo, de los refractos, ${ }^{37}$ lo cual contribuye a hacerlos más agradables en sus relaciones con sus semejantes. Ciertamente después del ejemplo que antecede es también fácil colegir que los reformadores de las costumbres no salen de este tipo. Su concepto de 10 moral surge de lo convencional, aceptado, definido socialmente, y no admite por tanto duda. Como resultado, no son pues amigos de "catequizar", de "meterse en lo que no les importa", pero por simpatía o participación emocional -espontáneamente - intervienen en situaciones en que ayudan a imponer la decencia o el orden. Tuvimos ocasión de referirnos al notable pasaje en un prostíbulo de Iquique en que la Petitpois acusa de ladrón a Lucho. En medio del lío, en el que las "blasfemias se confundían en un solo estridor soez", "al fin un mocetón se impuso. -A ver. ¡Ajo! Callarse. ¿Qué ha pasado?", mientras Lucho tiritaba de rabia y susto. Se suceden los cargos hasta que nuestro mocetón, juez natural en la trifulca, impone su sentir: "Bueno. Porquerías no tolero yo tampoco" (I, 242. 243). La cuestión se arregla de inmediato; las calumniadoras tratan de encontrar una escapatoria.

Junto con la inclinación por lo práctico, encontramos en estos personajes un natural amor y calor por el trabajo - que debe juzgarse de acuerdo a su posición en la escala social-, una energía práctica que en los casos mejores puede ser inspirada, aunque sin la tenacidad, lo consciente y la inspiración más elevada de ciertos refractos. ${ }^{38}$ Esta energía tranquila, práctica y sin mucho vuelo - que jamás oscila entre abulia y apresurarse más de lo necesario - la ejemplifica muy bien Teresa tal como corresponde a una persona situada muy abajo en la escala social. Luis quiere saber qué

37 Ya lo vimos en el ciclotímico de Kretschmer, al estudiar la tendencia contraria de los refractos (nota 20 ).

38 Ver cita de Kretschmer sobre el ciclotímico, nota ${ }^{25}$. 
hará ella con veintitrés pesos por todo capital, y Teresa responde: "Lo que hacemos todos los pobres. Buscar una casa de obreros, tomar allí pensión, servirles para comer más barato y ganarme la vida como se pueda en el oficio" (II, 175). Lo cual no le impide optar por convertirse en la mantenida de Luis cuando esto es lo más cómodo o conveniente, en quererlo a su modo, y abandonarlo cuando se convence o siente que la relación es insostenible. ${ }^{39}$

Teresa muestra también la alternancia de lapsos de depresión con períodos de alegría que Kretschmer señala en el ciclotímico - lo que estudia bajo "Die diathetische Proportion" (pág. I 19 y sig.), contrapuesta a "Die psychästhetische Proportion" (pág. 136 y sig.) del esquizotímico-:

De raro en raro, por ejemplo, ciertos atardeceres en los cuales por la lluvia no era posible irse de paseo, notaba Lucho, al tornar al nido, que Teresa estaba deprimida, silenciosa, con los párpados abatidos. Tenía entonces en la voz las inflexiones opacas de los descontentos. Diríase que con el tiempo turbio hubiesen revivido en su alma, solitaria el dia entero, las amarguras pretéritas, aquel fracaso que torció su porvenir.

$-i$ Qué te pasa, Tere?

- ¿A mí? Nada. ¿Por qué?

-Te veo... no sé cómo.

39 Barrios acentúa esta condición o la falta de ella en sus personajes con una terminología reminiscente de los escritores del noventa y ocho, muy de moda entonces en América: el pícaro de López, "francote tan rudo y tan generoso, [...] parecía poner acción, acción rápida, vigorosa y certera, hasta en el lenguaje" (II, 82); la Inés, la compañera de Teresa, en los últimos días antes de la huida de ambas, "estaba ya impaciente por que cesara [1a indecisión] y cediese su turno a la acción" (II, 251). Y en los otros: "venía la abulia del que embrutece" (II, 42); "soy un tipo sin voluntad" (I, 245); "teníanle cohibida, laxa la voluntad" (II, 82); "sabe Dios si no es cortedad ni consideración de consecuencias lo que le ha sujetado, sino su voluntad, que desmaya tanto, tanto..." (II, 153); "el sentir muv laxa ya la voluntad" (II, 156); "su voluntad ausente, nula" (II, 259); "mi voluntad era ya una cosa fofa" (I, 280) etc. La influencia del noventa y ocho parece también notarse en el encuentro del prọtagonista con la filosofía: "Leyó a Nietzsche y lo abandonó sin comprenderlo bien [aquí parece Baroja]. Siguió con Schopenhauer: era muy posible que el placer fuera sólo la ausencia del dolor" (II, 42-43). Hacia el final de la novela la desintegración de Luis se acompaña de un anhelo filosófico de no ser (II, 299 final y principio de 300); todavía lo repite, abreviado, la última vez que se ve con su hermana: "Necesito reposo, olvido. Necesitaría... el no ser" (II, 307). Otro indicio - irrefutable éste- de la influencia española o la atracción por lo español: en el lenguaje, además de los leísmos comunes en muchos americanos (no digo el leísmo porque entre los americanos es en su mayor parte snob y el natural lo les sale aquí y allá) y otros giros peninsulares, encontramos hasta laísmos de dativo, que repugnan al oído americano - "Luis Felipe habíala comprado una casa", "procurarla [a su mujer] una vida más acorde con su fortuna", "un día la hermana la dijo", "Lucho sólo veíala el brillo de los ojos", "la escribiría franco el haber perdido el empleo" (en este último ejemplo el laísmo convierte a una construcción irregular en ininteligible) (II, 120, 151, 182, 190 y 291 respectivamente). 
-El tiempo, los nervios. (II, 198-199. El subrayado no está en el original).

Luis continúa fijándose en ese estado de depresión sin causa racional o "motivo de reproche ostensible", y aun trata por un momento de reducir a algo razonable o consciente el estado temperamental de Teresa (el subrayado no pertenece al original):

-Hoy... parece que no me quisieras. ¿Qué te he hecho? Di, Tere... - iOh, no seas majaderito, no te pongas tonto!

-Dame un beso.

-Toma.

-Otro.

- Toma. :Ay, que niño eres, Lucho!

$Y$ él no continuaba, temeroso de hostigarla. Una como comunicación directa, fluidica, que le impresionase los nervios, le advertía que no era prudente proseguir.

Frente a Teresa Luis experimenta un sentimiento - "una pena medrosa", "temeroso de hostigarla" - parecido al que experimentamos frente a una fuerza elemental, ineludible, que no se puede desviar.

Lo que es un tema de observación común en algunos individuos de este tipo-el temperamento que parece cambiar con el tiempo o sin causa o control racional, el vigor de lo instintivo, de la parte animal en el hombre - ha sido desarrollado o acentuado en la ya antigua pero aún viva concepción de un tipo llamado "de naturaleza" por oposición a un tipo de principios o educación; recordemos en particular las intuiciones del prerromanticismo europeo, en especial las que siguieron a Schelling, las de Goethe y las letras subsiguientes. Los influjos naturales, los "flúidos magnéticos", las reacciones puramente temperamentales de un grupo de heroínas de Goethe - Otilia, Mignon, Clara - se siguen con análogos fenómenos en la Nela de Galdós de las letras españolas - "Marianela y Mignon se parecen, miradas con cierto cristal, como dos gotas de rocío", dice Clarín (Galdós, Madrid, I9ı2, pág. 63) - y tienen eco en muchos personajes de otras literaturas. Por un largo período la influencia del siglo de la educación se hizo sentir en que el tipo de principios prevalecía sobre el de naturaleza -así en Wilbelm Metister y Lals afinidades electivas (pero no en las tragedias de Goethe), así en Marianela y Fortunata y Jacinta (aunque Camila de Lo probibido ya apunta al enaltecimiento de la virtud natural). La Louise Roque de L'éducation sentimentale, de impulsos naturales y decididos, que habla patois y no tiene roce social ni lustre de edu- 
cación alguno, que quisiera montar a caballo contra las conveniencias de la época y que cuando el tibio Frédéric le pasa una mano por la cintura desfallece de un modo que hace recordar a Mignon con Wilhelm Meister - "un cri, suave comme un roucoulement, jaillit de sa gorge;"sa tête se renversa, elle défaillit, il la soutint" (pág. 373) --, Louise Roque decimos, es una criatura de esta familia - quizás el personaje de Flaubert más diferente y más descuidado por la crítica.

Y he aquí nuestra Teresa, de cabellera "de hembra sana" - "dos rizos rebeldes sobre la frente pequeña" (II, I673-, robusta "como la fruta fresca que divisa en la sombra el caminante" (II, I 72 ), de reacciones instintivas, temperamentales, recurrentes, que a veces se comporta "huraña, como azorada salvaje" (II, I84). La comparación con la fuerza natural la usa Barrios hasta con Anselmo, a la llegada del cual la "intimidad recogida desmenuzábase como a un soplo sobrado brusco. Su personalidad [la de Lucho], pues, sentíase desarraigada, sacudiéndose en ráfagas que serían muy alegres, pero que zarandeaban excesiva, excesivamente" (II, r35).

Barrios ya está decididamente - con Pérez de Ayala en las letras peninsulares - en la tendencia contemporánea, que reivindica la virtud o el poder de lo natural instintivo - de lo espontáneo-. Aquí debemos tomar nota de lo que ya se desprende del título de este ensayo, esto es, que no se puede probablemente encasillar influencias. Aunque si Goethe está directa o indirectamente alumbrando la senda de intuiciones, una senda que ya viene de más lejos, tanto o más allá aún que el Petratca. . ¿cuánto más lejos que el Banquete? Mejor es compararlas a una corriente, la cual irremediablemente alcanza a todo literato que ande explorando por el enmarañado, oculto valle de la propia y la ajena sicología.

\section{SEXO Y TIPO}

Y llegamos a Ias concomitancias sexuales de la distribución polar de los tipos, problema que aparece tan frecuentemente como el de esta misma clasificación de los tipos. Salió la palabra problema, y es que lo masculino-femenino no se convierte en tema, no absorbe de un modo más hondo y no comienza a revelar su sentido más profundo hasta que no aparece lo anormal, o menos normal o común en la relación entre el sexo y la personalidad. De varias maneras puede surgir lo problemático: el autor puede ver a los tipos de acuerdo a su relación normal -o más admitida en nuestra cultura-con el sexo, o sin perjuicio de lo anterior 
puede introducir algunos personajes - casi seguramente los principalesque se apartan de la norma; segundo, el autor puede en cambio retratar al hombre y a la mujer más o menos como son pero haciendo notar que debieran ser a la inversa (o da la imagen que considera "natural" pero se queja luego de que los hechos no confitmen esa imagen, lo cual viene a resultar lo mismo) - estos son los confusos, los mixed-up-; finalmente, el autor puede pertenecer él mismo a un tipo de excepción sin darse cuenta de ello y entonces presentar ingenuamente una imagen patas arriba de la frecuencia del tipo en la relación con el sexo. ${ }^{40}$

No vamos a desarrollar aquí con ejemplos las dos últimas posturas señaladas en el párrafo que antecede, ${ }^{41}$ pues se apartan del caso en estu-

40 Es posible a esta altura de los estudios sociológicos y sicológicos sintetizar los hechos observados desde diferentes enfoques, separar los que casan en el cuadro general de los que suenan estridentes o no acuerdan, $y$ valerse de este conocimiento sintético en sicología y sociología para.interpretar y valorar los ensayos anteriores - como los que se ejemplifican en este trabajo-. Para cerciorarse de hechos establecidos son muy importantes los estudios auspiciados por interés educacional, o necesidad de tratar con problemas de masa en la industria (especialmente con el aumento en la participación de la mujer) o investigaciones relacionadas con el comportamiento de soldados, o estudiantes, etc.; el estudio más integral sobre los sexos y vocaciones, ocupaciones, etc., todavía no superado en conjunto, son las pruebas sicométricas en Sex and Personality, publicadas en 1923 por Lewis M. Terman and Catherine Cox Miles. Sobre los tipos de personalidad condicionados por las normas y la sanción social, el libro de Margaret Mead Sex and Temperament in Three Primitive Societies (London, 1935). No desestimar a Havelock Ellis con su libro de hace dos tercios de siglo, Man and Woman (London, 1894), que en muchos aspectos es más fresco y objetivo que obras más en boga y recientes como Tipos sicológicos de C. G. Jung. Un excelente estudio integral es el de Viola Klein, The Feminine Character (London, 1946).

41 Pondremos una nota que nos ayude a ilustrar brevemente el punto por contraste. La segunda posición es la menos importante para estos estudios; es probablemente común en conversaciones pero es difícil de registrar - tal vez por ello la literatura de salón y de moeurs francesa sea uno de los sitios más indicados para hallar muestras; por ejemplo, un pensamiento de Madame de Girardin (siglo XIX): "La femme, la femme véritahle n'existe plus. Il y a encore des mères, [...] Il y a des soeurs. Il y a des maîtresses. Il y a des amies dévouées. [sigue la serie.] Mais il n'y a plues des femmes... dans le monde civilisé. En effet qu'est-ce qu'une véritahle femme? [Enumera una cantidad de virtudes y defectos, que merecen un estudio detallado.] Et maintenant où trouverez-vous donc beaucoup de femmes qui ressemblent à ce portrait-là? Hélas, il ne leur est plus permis, à ces pauvres femmes d'avoir tous ces charmants défauts; il leur a bien fallu y renoncer malgré elles, depuis le jour où les hommes eux-mêmes les leur ont pris. [Continúan las consideraciones.] (Marie Gasquet, Ce que les femmes disent des femmes [Americ-Edit., 1936], 202). Para la última postura - cuya posibilidad debe siempre considerarse en esta clase de intuiciones- (tener en cuenta los resultados de las indagaciones a que se refiere la nota anterior) sacaremos de la traducción de Revista de Occidente la concepción de E. Spranger: "Aquí es menester desarrollar una idea, que en Platón sólo está ligeramente indicada. La erótica puramente psíquica descansa en la polaridad de dos formas de las almas, cada una de las cuales necesita de la otra como su complemento. Lo ingenuo, lo natural, lo que florece en la inconsciencia de sí mismo, lo en sí itreflexivo [que Spranger asimila a lo femenino], siente el anhelo de la forma clara, fundada en el modelado consciente 
dio. Nos limitaremos a ilustrar la primera, en la que creemos que Barrios se encuentra situado. Eso sí, nos permitiremos traer algún ejemplo literario menos relacionado que los anteriores para ilustrar las notas comunes o extrañamente similares que suelen aparecer y que nos hacen pensar en una línea común de experiencia y tradición aun en literaturas alejadas; a través de esta comparación veremos también cómo el tipo excepcional en la mu. jer, es decir, la mujer cuya personalidad muestra aspectos masculinos, tiene al mismo tiempo características de las que mencionamos vinculadas a lo natural instintivo-el tipo de "naturaleza" por oposición al producto de la educación y los principios.

$A$ veces lo excepcional tan sólo se insinúa o se manifiesta como una faceta de la personalidad: Clawdia Chauchat en La montaña mágica de Thomas Mann - señora joven y atractiva, de la burguesía adinerada-, cuyas manos no son precisamente manos femeninas - anchas, con algo de pueril y primitivo, las uñas roídas (Der Zauberberg, Berlín, I925, I, I30I3I) - , de mirada magnética (I, 239), ojos color de montañas lejanas, que a veces se diluyen en un tinte nocturno, tenebroso, velado $(I, 246)$, y que cuando camina se desliza como un gato hacia el plato de leche ( $I$, 228), hace bolitas de pan en la mesa, da portazos como persona sin "educación" y sin duda se roe las uñas ( $I, 242)$; Hans la encuentra notablemente parecida a otra persona, y esa persona resulta un muchacho, antiguo compañero de escuela (subcapítulo "Hippe", I, I94 y I, 210); ella lo

de sí misma; lo en sí indiviso, y por ende oscuro, siente el anhelo de lo dividido, pero consciente de sí mismo. A la inversa, el espíritu maduro (o más maduro) siente el anhelo de lo naturalmente encubierto, con su hermosa fuerza plástica inconsciente. Estas dos formas de las almas, la unitariamente ingenua y la exclusivamente racional, peto cuidadosamente trabajada $-y$ apareciendo en muchos grados-, son como dos principios del universo. Podría llamárselas el principio psíquico-femenino y el principio psíquico-masculino" (Psicología de la edad juvenil, 2a. ed., 107). Está clato que Spranger intuye las mismas orientaciones generales que llamamos refracta y espontánea, y el punto que aquí nos interesa es que asimila lo masculino a la primera y lo femenino a la segunda. Interpretaciones parecidas encontramos en Simmel, Weininger ( $y$ hasta Jung se halla afectado) - parece general en el ensayo alemán después de Goethe-. Observemos de paso que estos ensayistas se han basado casi exclusivamente en la introspección para llegar a sus conclusiones, de modo que la posibilidad de coincidir con los hechos generales depende de que su propia siquis, personalidad, no sea excepcional o esté organizada de acuerdo al modo más frecuente en el sexo contrario. Esto ya en un principio no se cumple, pues las indagaciones de Terman-Miles y trabajos posteriores (ya entrevisto en $\mathrm{H}$. Ellis) prueban que los intelectuales, los artistas, los que aparecen en $W$ bo is $W$ bo, son claramente más femeninos que el término media de los hombres de su clase social. Y lo anterior aun se complica con la tendencia del refracto a la generalización; como dice Baroja, "el hombre romántico se forja un tipo de la mujer que no comprueba nunca" (El gran torbellino del mundo [Caro Raggio], 40). 
mira a Hans de un modo directo no propio de la mujer en su esfera social $(\mathrm{I}, 2 \mathrm{IO})$.

William Faulkner en The Wild Palms va más allá de la insinuación: Charlotte también tiene manos varoniles - anchas, romas, fuertes, de dedos ágiles, con uñas tan cortas como si se las royera (New York, 1939, págs. 40-4I ) - que parecen callosas - en el estilo de Faulkner (vacilación y perfeccionismo) "not calloused exactly but smoothly hardened and toughened like the heel of a foot" (pág. 42)-, de apretón simple, firme y sin escrúpulos (pág. 39); la primera vez que mira a Harry, "he saw that her eyes were not hazel but yellow, like a cat's, staring at him with a speculative sobriety like a man might" (pág. 39); su cuerpo tiene la "broad, simple, profoundly delicate and feminine articulation of Arabian mares" (pág. 38); Harry ve por primera vez su letra, "in a big sprauling untrained hand such as you associate at first glance with a man until you realise an instant later it is profoundly feminine" (pág. 8I); más adelante Harty dice "she's a better man than I am" (pág. I33), "she is a better gentleman than I am, too", "and maybe I can be the consort of a falcon, even if I am a sparrow" (pág. I4I), y aun repite "she is not only a better man and a better gentleman than I am [... ]" (pág. 207); a veces se nota el esfuerzo de Faulkner por insinuar -o estudiar- notas masculinas en el carácter de Charlotte: cuando se nos aparece por primera vez en la novela es con un sobrenombre masculino - "someone behind said, 'Here's Rat and Charley" " (pág. 38), hay que releer para darse cuenta-; lleva los vestidos como quien llevara puesto un overall (pág. 42); lenguaje rudo; una falta de pudor en el lenguaje que ninguna mujer común mostraría en la situación en que lo hace Charlotte (pág. 50); ha sido la única niña en su familia, entre varios hermanos varones, y tiene cicatrices de una quemadura - "when I was seven years old I fell in the fireplace, my brother and I were fighting" (pág. 40), lo cual sugiere una niñez de tomboy.

En el ejemplo siguiente, de Baroja, las notas de "naturaleza" se acentúan, mientras que las masculinas apenas se insinúan: Maria de Aguiree en Las inquietzudes de Shanti Andia, de mano callosa (Madrid, rgri, págs. I73, 178), la primera vez que la vio Shanti "tenía los cabellos despeinados por el viento, la ropa mojada por la lluvia; en sus ojos se leía una decisión huraña y melancólica" (pág. 172); de muchacha era una salvaje -otra vez el marimacho- que andaba por las peñas tirando piedras (pág. I76); habla en vascuence de modo que parece una aldeana que no hubiera salido del pueblo (pág. I77); marcha al lado de Shanti por las piedras del Izarra con agilidad de campesina (pág. I86); en su 
mirada se expresa alternativamente la timidez, la audacia y el enfado, y pasa de las lágrimas y la desesperación a la sonrisa y el buen humor (págs. I86-187); su amiga más íntima, Quenoveva, es "una muchacha igualmente salvaje" (pảg. $\mathrm{I}_{7} 6$ ), fuerte, valiente, tímida, con las cejas un poco juntas, y grita como un hombre (págs. 176-177).

Aquí debemos detenernos en Camila, "la mujer más hembra, más graciosa, más viva y fuerte que ha pintado hasta ahora ningún novelista español moderno" (Clarín, ob. cit., pág. r44), quien resulta al final la persona más decente en Lo probibido, aunque de ella dijera su padre: "es la menos favorecida en dotes morales. No es esto decir que sea mala [...], la hemos mimado más de la cuenta y nos ha salido mal educada" (Obras Completas, IV, I688). "Su mamá $[\ldots]$ aseguraba que era aquello pura inocencia y desconocimiento absoluto del mal" (pág. I692). La opinión de su primo: "Serían tal vez inocentes sus desfachateces, pero no lo parecían [...] Era una escandalosa, una mal educada, llena de mimos y resabios $[\ldots]$, todo lo que sentía lo expresaba con la sinceridad más cruda" (pág. I69I) - muy a menudo le choca el lenguaje desbocado y terriblemente obsceno de Camila-. "Otras veces dábale por ponerse triste y llorar sin motivo [...] (pág. I692). De las citas que anteceden como de las que vienen a continuación está claro que Galdós hace resaltar lo espontáneo y lo indomablemente franco - de un pieza - de este carácter como rasgos de "naturaleza", contrapuesta a principios o educación: "Era la menos guapa de las tres hermanas [ dice su primo José María Bueno de Guzmán, quien acabará enamorado de ella - "poco guapa" como la Charlotte americana, como Louise y Teresa, pero la más atractiva al mismo tiempo; el retrato físico a continuación coincide en más de un punto con el de Teresa-1, bastante morena, esbeltísima, vigorosa, saludable como una aldeana, y se jactaba de que jamás un médico le había tomado el pulso. Su agilidad era tan notable como aquella coloración caliente, sanguínea, de su piel limpia y tostada, indicio de gran poder físico" (pág. 1692). Y lo que sigue, sencillo como suena, es notable: "No podía [José María] soportar aquel carácter que era la negación de todo lo que constituye el encanto de la mujer. La discreción, la dulzura, el tacto social, el reposo del ánimo, el culto de las formas, éranle extraños" (pág. I692).

Las coincidencias suenan y vuelven a sonar aquí y allá como sorprendentes ecos. No vayamos a Flaubert y a Barrios sin antes recordar lo que ya dijimos, que Goethe está a cierta altura alumbrando las intuiciones vinculadas al "tipo de naturaleza", pues haremos valer aquí el mismo juicio con relación a lo masculino-femenino, especialmente en lo que atañe 
a la mujer excepcional que muestra a la vez los rasgos de "naturaleza" contrapuesta a educación. Goethe reconoció en la mujer - como su "elemento" (Werke [Bong], VIII, 7) - la coherencia, la conciencia, lo razonable; así define a su sexo Charlotte, y su marido Eduardo le acepta el punto sin importársele en realidad gran cosa, en las disquisiciones del capítulo primero de Las afinidades. Ottilie - en la misma novela - no casa con aquella definición de Charlotte del carácter femenino y es al mismo tiempo la criatura de "naturaleza" por excelencia, con todos los altibajos temperamentales, el "magnetismo", los influjos naturales, también la coor. dinación muscular - "Ottilie, leicht schreitend, ohne Furcht und Ängstlichkeit, im schönsten Gleichgewicht von Stein zu Stein ihm folgte"-, "2 y algo notable: al mismo tiempo que una organización síquica no típicamente femenina, muestra una naturaleza esencialmente mujer, quizá más mujer que el tipo corriente femenino - "konnte er sich nicht vcrleugnen, dass es das zarteste weibliche Wesen sei, das ihn berührte" —, ${ }^{43}$ enigma éste que también resulta evidente en todos los ejemplos que anteceden. ${ }^{44}$ (Saltémonos aquí a Mignon, esa criatura medio mito medio mujer, con la misma mezcla de ideación y motilidad masculina y naturaleza archifemenina).

Flaubert también presenta tipos excepcionales en relación al sexo. Esta vez el personaje principal es varón y tendremos ocasión de ver que del mismo modo como el carácter espontáneo parece no corresponder a la

42 VIII, 44. Otilia caminaba ágilmente, sin temor ni inseguridad [angustia, sobresalto], y lo seguía de piedra en piedra, con el más bello equilibrio. (Kretschmer señala la torpeza de movimientos, lo desgarbado, la ineptitud para los ejercicios gimnásticos, en su esquizotímico, en el último párrafo de página 146).

43 VIII, 45. No pudo menos de reconocer que era [literalmente] el más tierno y femenino ser que lo hubiera tocado.

44 Ia clave de esta aparente contradicción está en que el tipo refracto es en realidad un tipo atemperado, amortiguado, con respecto a la expresión, a la exteriorización del temperamento o naturaleza de cada uno, hombre o mujer. El raciocinio, la conciencia y deliberación que suplen un vacío o simplemente intervienen de una manera absorbente en el gobierno de los actos, neutralizan a la vez el temperamento básico. Lo que se desprende de estas intuiciones literarias - como asimismo de una traducción de las escalas de Terman-Miles y demás trabajos de este tipo- es que el tipo espontáneo (en el que el temperamento se expresa más directamente) es más frecuente en el varón, y que el refracto abunda más en la mujer. Ahora bien: una mujer de tipo espontáneo tendrá su temperamento, naturaleza, más a flor y por tanto, aunque le falte el tacto, la discreción, "el culto de las formas" (Galdós), to "razonable" (como la Charlotte de Afinidades, la del Werther) de la estructuración corriente femenina - necesarios a su papel en nuestra sociedad-, se revelará por otra parte o más "hembra" (como la Charlotte de Faulkner, la Clara de Goethe [Egmont], Camila, Teresa) o más zarteste weibliche (como Otilia, Mignon, María de Aguirre, la Clara de Galdós [La fontana de oro] - ¿no hay también algo de goethiano en el lío que uno se hace a veces con estos nombres?-) o un poco de lo uno y de lo otro (como Louise Roque) - -aunque ambos aspectos se dan en todas si las estudiamos prolifamente. 
común organización sicológica femenina, el refracto extremo parece estar alejado de lo que nuestra cultura entiende por varonil. Mientras Frédéric trata de calmar a Louise, ella "lui mit ses deux mains sur les épaules pour le mieux voir en face, et, dardant contre les siennes ses prunelles verts, d'une humidité presque féroce: -Veux-tu être mon mari?"' (pág. 373); Frédéric en cambio, que se siente enamorado de Mme. Annoux y cuando ella misma parece preferirlo a su propio marido, no da ningún paso que lo acerque a la posesión de la mujer - en la que se entretiene imaginativamente de todos modos_, "il voulait qu'elle se donnât, et non la prendre" (pág. 400). Ya mencionamos que Louise quiere montar a caballo contra las conveniencias de época, a lo que agregaremos que lo que añora es en realidad hacer lo que le dé la gana_- "autrefois, on me laissait faire tout ce que je voulit; à présent, rien!" (pág. 368). Por otro lado el autor define a "certains hommes", para los cuales la acción "est d'autant plus impraticable que le désir est plus fort. La méfiance d'eux mêmes les embarrasse, la crainte de déplaire les épouvante; d'ailleurs, les affections profondes ressemblent aux honnêtes femmes; elles ont peur d'être découvertes, et passent dans la vie les yeux baissés" (pág. 260-26I). La relación entre los amigos intimos Deslauriers y Frédéric es muy significativa; en varios pasajes se insinúa lo femenino en Frédéric: "Frédéric, en apercevant Deslauriers, se mit à trembler comme une femme adultère sous le regard de son époux" (pág. 80); esto no es sólo una figura literaria, más adelante, Deslaurier "songea à la personne même de Frédéric. Elle avait toujours exercé sur lui un charme presque féminin [...]" (pág. 362); el último capítulo se consagra a esta amistad (el subrayado es nuestro): "vers le commencement de cet hiver, Frédéric et Deslauriers causaient au coin du feu, réconciliés encore une fois, par la fatalité de leur matune qui les faisait toujours se rejoindre et s'aimer" (pág. 6r3). ${ }^{45}$

45 Frédéric muestra imaginaciones o actitudes en el linde de lo sexualmente anormal. Durante el tiempo en que Frédéric y Deslauriers comparten la vivienda en París, los muchachos se comunican sus ambiciones, sus sueños para lo futuro, y "Frédéric se meublait un palais à la moresque, pour vivre couché sur des divans de cachemire, au murmure d'un jet d'eau, servi par des pages nègres" (pág. 95) - una fantasía de tinte voluptuoso y ocurrírsele pajes negros en lugar de odaliscas, esposas, huries...-; tal vez estemos hilando demasiado fino, pero cualquiera que haya convivido con muchachos italianos, españoles o franceses -latinos en generalsabrá que el tema de la mujer está entre ellos siempre presente. Hacia el fin de la historia, en la última entrevista con Mme Arnoux 'Frédéric soupconna Mme Arnoux d'être venu pour s'offrir; et il était repris par une convoitise plus forte que jamais, furieuse, enragée. Cependant, il sentait quelque chose d'inexprimable, une répulsion, et comme l'effroi d'un inceste". ¿En qué relación es Marie Arnoux bermana de Frédéric? ¿En el parecido espiritual, el tipo general de personalidad?-esto podría impedir el amor si el amor es el complementarse de tipos opuestos (como se intuye en las letras occidentales desde Platón hasta la fecha, y sobre esta base podríamos 
En Un perdido el autor también nos insinúa a veces y a veces nos señala en forma clara las notas del carácter que no corresponden a lo típico o más frecuente del sexo. Teresa y la Ana Portela muestran rasgos mas. culinos del carácter - fuerza, determinación, coraje, prontitud y espontaneidad - en su relación con Lucho; el ya citado episodio del burdel muestra el contraste entre Lucho y la Ana -ésta parece allí el hombre, y su compañero la mujer-; más adelante Robles lo pone en palabras francas referentes a la relación entre Teresa y Luis: "tú has parecido allí la mujer" (II, 226). El factor educación en boca del padre de Lucho: "¿lo están criando afeminado $[\ldots]$ ?.' (I, 66). El comportamiento y la actitud de las prostitutas con Lucho y de éste mismo con ellas: "Muchas veces, el calor sofocaba, y la Meche hacía que Lucho se quitara el traje de casimir, más caluroso por ser de luto. Le ponía, en cambio, una de sus batas. Y las mujeres, muy divertidas, prorrumpían en bromas: 'Tenemos niña nueva iViva la Luchita!'..." (I, 209). Las sugerencias del autor cobran significado por su repetición: sus amigos "le tildan 'raro'" (II, I5I); "había llorado como una mujer" (I, 227). Y expresamente: "Empezó así a nacer en él cierto menosprecio por el corazón masculino y una inclinación engreída hacia las mujeres, cuyos corazones, un tanto simples, acor-

concluir que el sentimiento de Frédéric no fue nunca amor), pero la inhibición es aquí sexual (tanto más si el sentimiento de Frédéric no es amor), o de amar Frédéric a Marie Arnoux no habría pudor que no se derrumbara al embate de un caudal de pasión acumulado durante toda una vida (y enfermedad de "voluntad" -apetito- sería en este caso sinónimo de enfermedad de sexo). En cuanto a la atracción de dos personalidades masculinas que Flaubert presenta, no es fácil concluir sobre el tipo opuesto o complementatio en las mismas tal como Alfred Colling lo hace en una sola frase - "Dans L'Ëducation sentimentale, il [Flaubert] reprend donc ce thème cher de deux personnalités masculines s'attirant, s'opposant et se complétant l'une par l'autre" (Gustave Flaubert, Paris, 1941, 281). En el estudio que citamos en la nota ${ }^{15}$ (tesis para el Doctorat en medicina) Philibert de Lastic observó que lo diferente en ambos es que Deslauriers "est loin d'être un aboulique comme Frédéric"; pero a continuación: "et néanmoins le résultat de son passage à travers la vie sociale indique, par ses résultats négatifs, une faculté d'adaptation tout aussi faible que chez son ami. [...] On peut $[\ldots]$ trouver chez lui une autre forme, tout aussi défectueuse, de la volonté, où l'apport des contingences devient trop faible [la división, desconexión esquizoide] pour dévier d'une façon appréciable la direction de la résultante des tendances idéo-motrices acquises ou innées, qui constituent le caractère" (pág. 73). Arnold Chapman ("The Perdido as a Type in Some Spanish-American Novels", PMLA, LXX, 19-36) ha acertado al ver la similitud básica que existe entre estos dos personajes (en lugar de oposición o complemento): "Moreau is in reality a dual character, the two sides of which Flaubert employs to declare that fate selects no special victims. Moreau's alter ego is Deslauriers who, though using diametrically different tactics comes out at the same place in the end"' (págs. 20-21). Volvemos a la página 74 de de Lastic: nous allons retrouver sous d'autres formes et pour d'autres causes cette même impossibilité de l'adaptation, cette insuffisance de la fonction du réel [...]"; y a continuación se ocupa de los demás personajes de L'éducation sentimentale, para probar que todos ellos muestran la misma personalidad básica. 
daban mejor con el suyo" (I, 208). Anselmo había nacido "con vocación o ductilidad para todas las carreras que por lo general los hombres adoptan. El, por el contrario [el subrayado es nuestro], se juzgaba extraño a la mayoría de los ambientes [...] ¿Era él un ser absurdo?”' (II, 5r).

\section{BARRIOS Y LA INTUICIÓN DE LOS TIPOS}

Volvamos atrás unas líneas, consideremos nuevamente la observación de Barrios: "seres nacidos con vocación o ductilidad para todas las carreras que por lo general los hombres adoptan". Está claro que tenemos aquí una observación ( + intuición) más una serie de consideraciones de matiz científico: nacidos, en que se afirma el tipo como innato; la disyuntiva vocación o ductilidad ("ductilidad = facilidad, aptitud); por lo general en ademán de estadística, y su relación con las carreras, que sugiere un enfoque behaviorista del problema. Las escalas de Terman-Miles (hasta hace poco sólo conocidas por especialistas) aparecieron varios años después de la primera edición santiaguna de Un perdido (ver nota anterior 40). ¿Se trata de una intuición de Barrios? Indudablemente, pero sabemos que las instituciones no vienen del aire. Una serie de observaciones y afirmaciones como la que antecede no podría surgir de un autor que no se interesara activa y constantemente en sicología -en la propia y en la ajena-. Y repetimos activamente porque no se trata aquí del común hablar por boca de ganso. No es pues el de Barrios tanto un interés en "sicología" cuanto el interés en la introspección y en las sicologías que lo rodean -en la observación directa, inmediata, que produce síntesis valiosas y originales.

La conclusión a que aquí llegamos ya se desprendía de lo que vimos bajo "El autor y el tipo" - en particular lo referente al interés del personaje Lucho por las sicologías circundantes--. En suma, creemos que en las páginas precedentes hemos apteciado una serie de vistas -algunas en detalle, otras que nos llaman a nuevas exploraciones-:

I - En la misma novela que ha sido a veces tildada de "autobiográfica", Barrios en realidad ha creado una riquísima variedad de caracteres, distribuidos polarmente en dos tipos generales;

2- En la visión de esos tipos y la consideración del sexo muestra coincidencias notables con otros autores modernos;

3-El solo hecho de esta bifurcación de los caracteres excluye toda afirmación de excesivo peso de lo autobiográfico en la obra de Barrios, pues ni siquiera en general podría asimilárselo a por lo menos uno de los tipos a que pertenecen sus personajes; en este aspecto-particularmente 
en $U n$ perdido - sobrepasa a Flaubert y a la mayoría de novelistas de sicología, cuyos personajes pertenecen salvo contados casos a un solo tipo (notas 36 y 45 );

4 - Si en lo general podemos afirmar lo que antecede, la atención, la riqueza y la precisión en el detalle sicológico distinguen a Barrios de la generalidad de autores interesados en este problema (tal como se desprende de los ejemplos de Un perldido y de lo que apuntamos en la nota 36 );

5 - En las afirmaciones de matiz científico - originales, adelantadas en relación a su tiempo ( $y$ que no sobran demasiado en la novela gracias a su brevedad) — sólo encontramos un precedente, en el interés semejante de Goethe;

6 - Sus intuiciones, de acuerdo a lo que señalamos con respecto a la investigación última - notas $40,4 \mathrm{r}, 44-$, concuerdan con lo comprobado a la fecha, en un campo donde el ensayo sicológico ha errado repetidamente.

Quisiéramos que estas páginas pudiesen estimular el interés en la notable similitud de experiencias de escritores - algunos próximos, otros distantes-y contribuir al reconocimiento universal de la importancia que a la obra de Eduardo Barrios corresponde en la novela sicológica.

ÁNGEL M. VÁZQUEZ-BIGI, Universidad de Nortbern Illinois. 